\title{
Jordanian Oil Shales: Variability, Processing Technologies, and Utilization Options
}

\author{
Hani Muhaisen Alnawafleh ${ }^{1,2}$, , Feras Younis Fraige ${ }^{1,3}$, Laila Abdullah Al-khatib ${ }^{1}$, \\ Mohammad Khaleel Dweirj ${ }^{1}$ \\ ${ }^{1}$ Faculty of Engineering, Al-Hussein Bin Talal University, Ma'an, Jordan \\ ${ }^{2}$ Faculty of Engineering, Tafila Technical University, Tafila, Jordan \\ ${ }^{3}$ Faculty of Engineering, King Saud University, Al-Muzahmiayah Branch, Riyadh, Kingdom of Saudi Arabia
}

\section{Email address:}

hanialnawafleh@ahu.edu.jo (H. M. Alnawafleh)

\section{To cite this article:}

Hani Muhaisen Alnawafleh, Feras Younis Fraige, Laila Abdullah Al-khatib, Mohammad Khaleel Dweirj. Jordanian Oil Shales: Variability, Processing Technologies, and Utilization Options. Journal of Energy and Natural Resources. Vol. 4, No. 4, 2015, pp. 52-55.

doi: $10.11648 /$ j.jenr.20150404.11

\begin{abstract}
Jordan has a huge Oil Shale (OS) reserves with about 50 billion tons are located in the central part. Oil Shale is considered the only potentially discovered fossil fuel in Jordan. Jordanian OS is characterized by its good quality, near surface deposits with low stripping ratio. The main deposits are located in central Jordan with good road network and effectively thin population. On general, the reported physical and chemical properties suggest vertical variability pattern within the same deposits and lateral variability between the deposits. Extraction behavior also confirms such variability. The dependency of Jordan on imported crude oil and gas put extra pressure on the Jordanian economy as a result of the heavy and yet growing energy bill. The Jordanian government shows interest in commercializing its potential OS reserves and signed many agreements and memo of understanding with many external companies' expert in OS processing, such as Shell international. In this work, the variability of Jordanian OS will be investigated with reference to the current status on their processing and utilization options.
\end{abstract}

Keywords: Oil Shale, Jordan, Variability, Utilization, Processing

\section{Introduction}

Jordan has a huge oil shale (OS) reserves spread over the country. More than 50 billion tons are located in the central part (Fig. 1), and with unlimited OS quantities are reported in the north of the country [1]. Oil shale deposits are found in several horizons mainly that of upper Cretaceous Muwaqqar Chalk Marl Formation with more than $350 \mathrm{~m}$ in the Yarmouk area [2-4].

The upper Cretaceous OS in Jordan is not true shale but bituminous carbonate [5]. The inorganic constituents are: carbonates, clays, silica, phosphates, and sulfur. On the other hand, the organic matter fraction, which may exceeds $25 \%$ wt in some horizons, is essentially kerogen with low quantities of bitumen [6].

Oil shale is expected to play crucial role in Jordanian economy in the near future. The exploration for commercial OS deposits in Jordan was started since more than four decades (e.g. [7]), as early as 1980 and later, the research continued through many geologic and technologic studies for evaluation and utilization purposes (e.g. [8]). It is the purpose of this paper is to highlight the status of Jordanian OS deposits, especially those in central Jordan, in terms of their variability, processing technologies and utilization options.

\section{Methodology}

To illustrate the variability of Jordanian OS deposits, data available from the Natural Resources Authority (NRA) have been reviewed and analyzed. Certain important figures therefore constructed. Experimentally, and for the purpose of examining OS variability, three OS samples were provided from different OS deposits in central and south Jordan (namely; El-Lajjun, Sultani, and Jurf Ed-Darawish) (Fig. 1). About 2 grams of finely ground $(<150 \mu \mathrm{m})$ OS samples were soxhlet extracted for 24 hours using $200 \mathrm{ml}$ Tetrahydrofuran. The shale oil yield data then were recorded. 


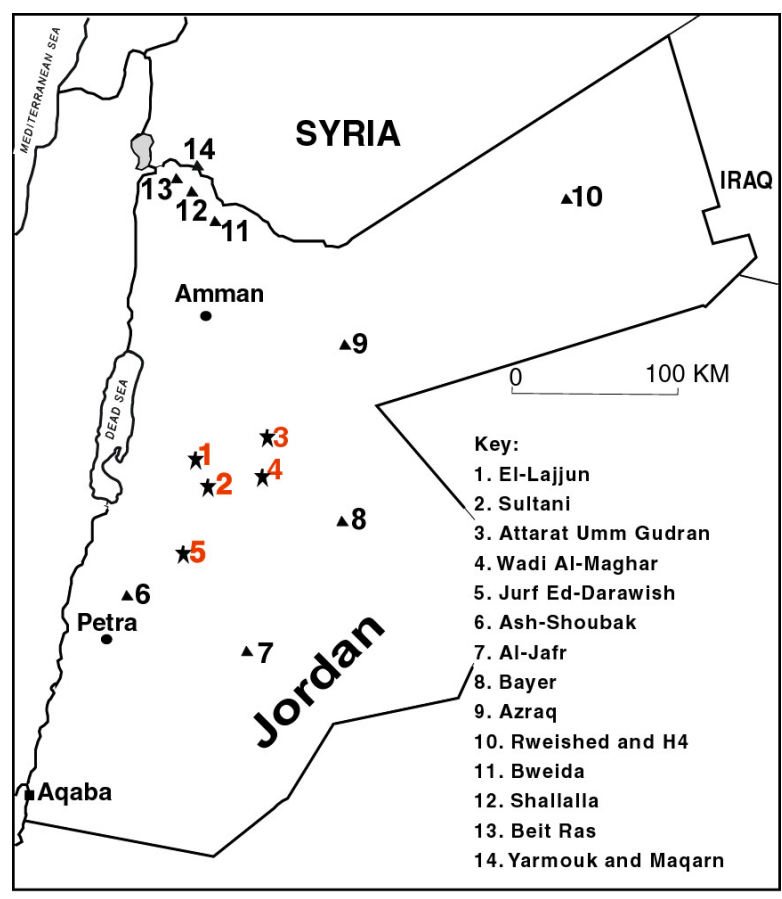

Figure 1. Oil Shale distribution in Jordan. Central Jordan oil shale deposits are highlighted in stars.

\section{Oil Shale Variability}

\subsection{Geologic Variability}

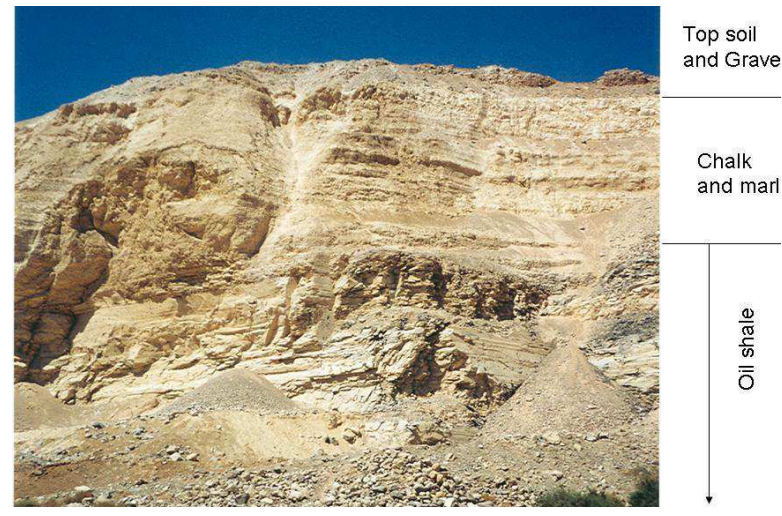

Figure 2. Local oil shale outcrop in El-Lajjun area, Central Jordan.

The geologic variability of Jordanian OS is studied in detail by [5]. The author reported the variability in terms of their rock types, chemical and physical properties, and beds thickness. In central Jordan, OS deposits are found in localized basins [9]. The upper most part of OS succession is locally exposed (e.g. Fig. 2). In selecting the future OS processing technology, this variability should be considered.

\subsection{Lateral Variability}

Oil shale in central Jordan has variable thickness and stripping ratio (Fig. 3). To highlight the OS variability, Fig. 3 and later figures, except Fig. 6, are constructed from the average data of OS analyses results of various chemical and physical laboratory tests performed by the NRA and reported during the year 2006 by [10] from the NRA team.

In central Jordan, the OS deposits are quite near surface where the stripping ratio ranges between 1 to1.6. Relatively low stripping ratio indicates the suitability of surface mining techniques for OS extraction. Thickness variability is related to different geologic and formational conditions as discussed by [5] and [9].

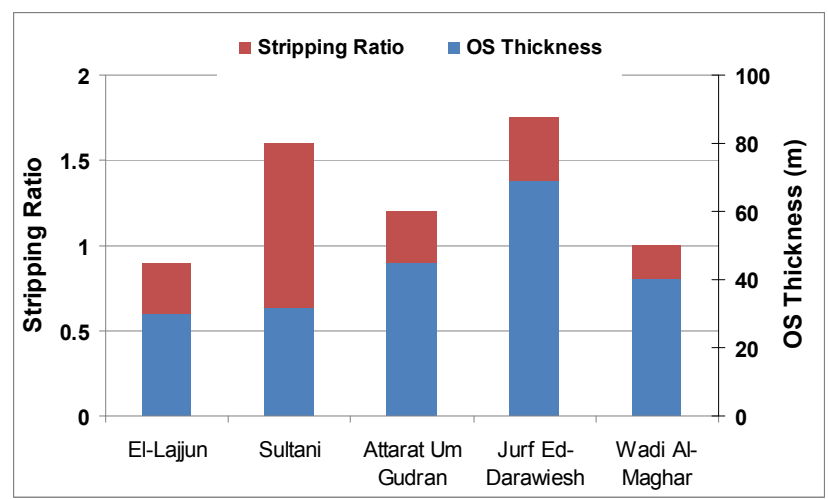

Figure 3. Thickness and stripping ratio variation across central Jordan oil shale deposits.

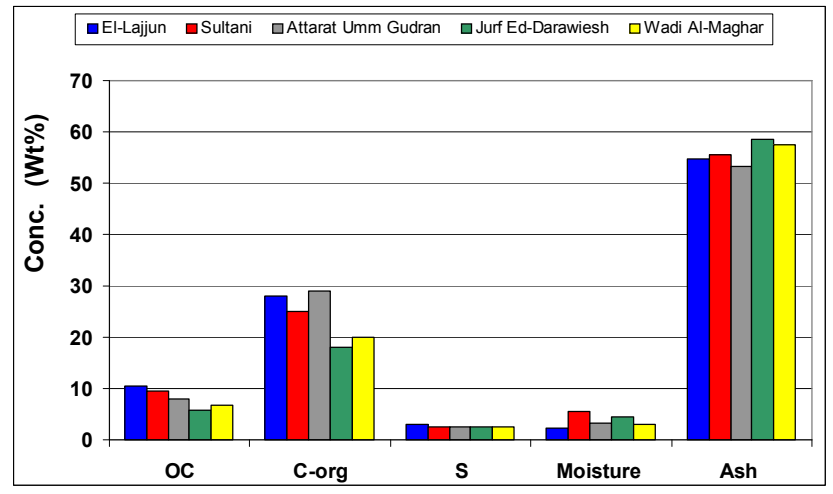

Figure 4. Variability in some chemical and physical properties of oil shale deposits in central Jordan. OC: average oil content. C-org: average organic carbon content. S: Sulfur.

The chemical and physical variability between the main OS deposits in central Jordan is illustrated in Fig.4 and Fig. 5 respectively. The average oil content varies between 5.7 to $10.5 \%$ by wt. High total organic matter content can be inferred from the high organic carbon values that may reach up to $29 \%$ by wt. at the OS deposit of Attarat Umm Gudran. The $\mathrm{SO}_{3}$ and moisture contents rise up to $5 \%$ and $3.8 \%$ by wt. respectively. Such variability in the chemical and physical properties indicates different quality for different OS deposits. Therefore, careful method selection is needed when considering such deposits for utilization.

The major inorganic fraction is the carbonate as indicated from the $\mathrm{CaCO}_{3}$ content that varies in the range of $47-69 \%$. Other important fractions indicated from the values of major oxides presented in Fig.5 are quartz, clay, phosphate, and 
sulfides.

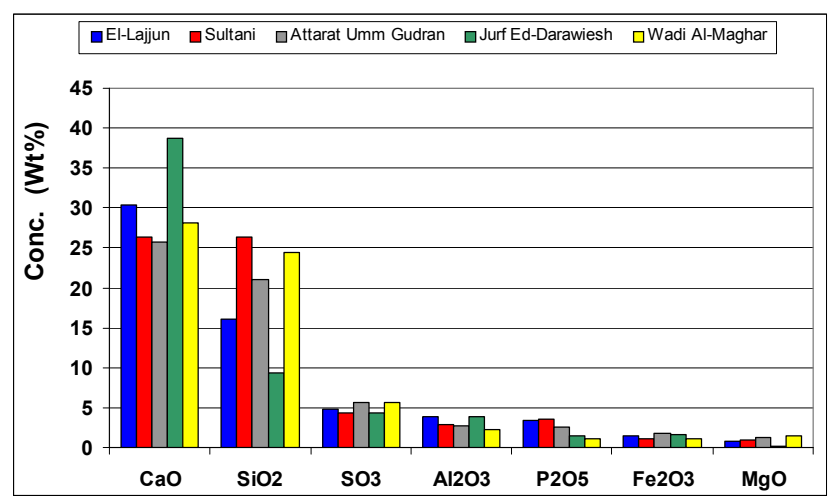

Figure 5. Variability in the chemical composition (major oxides) of oil shale deposits in central Jordan.

The variability of Jordanian OS deposit can be inferred from the results of the solvent extraction on selected oil shale samples from different deposits (Fig. 6). Such extraction variability indicates different composition of OM between OS deposits that must be taken into consideration in future utilization opportunities especially if certain extraction methodologies need to be applied.

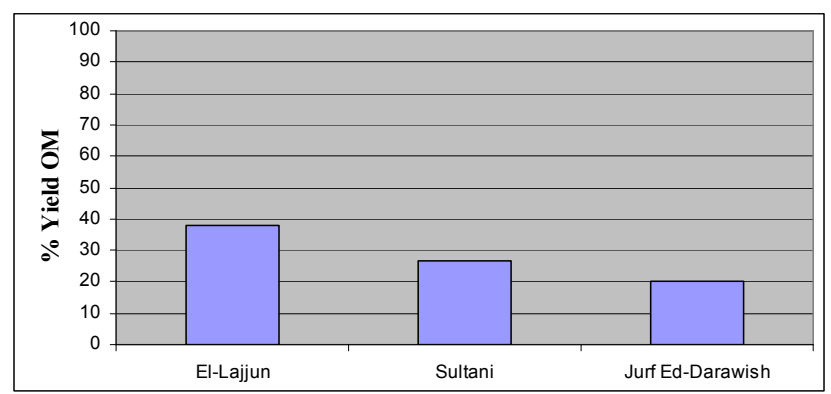

Figure 6. Variability in organic matter yield \% resulted by soxhlet extraction on oil shale deposits in central Jordan.

\subsection{Local Variability}

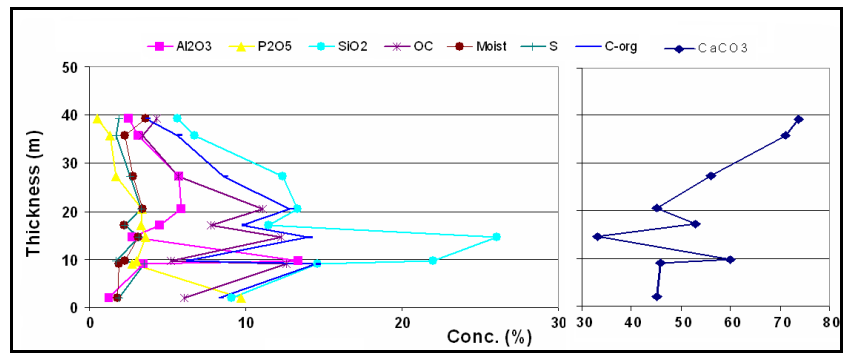

Figure 7. Vertical variability in some physical and chemical composition of El-Lajjun OS deposit, central Jordan.

To test the variability within the same deposit (e.g. ElLajjun OS deposit), the physical and chemical properties are found to be vertically variable (Fig. 7). This variability indicates that the deposit is not uniform and such variability complicates the potential utilization methodologies. Change of formational conditions is the main reason for such variability [5]. High carbonate and sulfur contents play a crucial role in the selection of future processing technology. Such content of these two fractions resulted in lowering the OS quality. Many issues may arise from their presence during the OS processing. Therefore, they are considered as major obstacles facing any progress in the Jordanian OS utilization.

\section{Processing and Utilization Options}

The interest in OS resources in Jordan developed due to the fact that Jordan energy sector is totally dependent on the imported crude oil. The dramatic increase of imported oil put extra pressure on the country economy. Therefore, the government of Jordan is seriously considering the exploitation of the country's potential OS resources. The NRA has conducted various OS assessment studies since 1980. In addition, a number of international collaborative works has been completed. Such work covered the suitability of current OS processing technologies and the application of international expertise to develop the Jordanian oil shale industry.

The main collaborative work with international companies is clearly reported in literature. For instance, Besieso [11] have summarized the previous work on the exploitation and use of the Jordanian OS resources such as the work of Klockner/Lurgi and Suncor. Since 2005, the Jordanian government has implemented a long term strategy for energy sector in Jordan including OS resources. Such strategy has aimed to attract foreign investors and to create several investment opportunities in the OS sector include OS feasibility studies, mining and exploitation of deep and near surface deposits and their processing [11]. Such strategy has succeeded and several agreements have been singed such as the agreement with Enefit and Shell companies.

Previous work conducted so far on the Jordanian OS has considered the Jordanian OS as a suitable source of energy due to its high organic content. The identified OS resources are enormous and will cover the Jordan's energy need for hundreds of years [11]. Jaber et. al. [12] summarized the most important factors in the Jordanian oil shale development. In their comprehensive study, all aspects regards the OS utilization are fully discussed. Jaber et. al. [12] stated that the costs of available extraction and processing technologies, the quality of the markets for the products and by-products, the implication of social and physical environments development, and health and environmental regulations are the major factors might affect Jordanian OS commercialization.

Technical research and exploration studies conducted so far on Jordanian oil shales proved their suitability for retorting or direct combustion without taking into account the OS variability. Retorting should take into account the high sulphur content. Direct combustion is favored if high sulphur content is overcome and combustion occurs at temperatures less than that of the deformation temperatures of carbonate. At the mean time, many technical and environmental issues 
would delay the OS utilization. At this point, and within the available OS processing technologies, the research on the OS resources in Jordan may be diverted to more environmentally-friendly techniques such as supercritical fluid extraction.

\section{Conclusion}

Jordanian OS shows local and lateral variability. Oil shale in central Jordan reveals relatively high oil content, relatively low moisture and majoring of carbonate and silicate phases with sulphur content of approximately $3 \%$ wt. The OS variability should be taken into account in selecting the most relevant processing technology.

\section{References}

[1] Dyni, J. 2005. "Geology and Resources of Some World OilShale Deposits". USGS Report 2005-5294.

[2] Abed, A.M.; Arouri, K,; Amiereh, B.S.; and Al-Hawari, Z. 2009. Characterization and Genesis of Some Jordanian Oil Shales. Dirasat, Pure Sciences, Volume 36, No. 1. Pp 7-17.

[3] Jarrar, M. and Mustafa, M. 1995. Mineralogical and geochemical study of the oil shale of Wadi Esh-Shallala (NJordan). Abhath Al-Yarmouk "Pure Science and Engineering Series". Vol. 4.2 .Pp 111-36.

[4] Pufahl P. K., Grimm K. A., Abed A. M., Sadaqah R. M. Y. (2003). Upper Cretaceous (Campanian) phosphorites in Jordan: implications for the formation of a south Tethyan phosphorite giant. Sedimentary Geology, vol 161. 175 - 205.
[5] Alnawafleh, H.M. 2007. Geological Factors Controlling the Variability of Maastrichtian Bituminous Rocks In Jordan." PhD Thesis. The University of Nottingham, UK.

[6] Abed, A.M. and Arouri, K. 2006. Characterization and Genesis of Oil shales from Jordan. International Conference on Oils Shale: "Recent Trends in Oil Shale", 7-9 November, Amman, Jordan. PAPER NO. rtos-A121.

[7] Speers, G. C. 1969. "El-Lajjun Oil Shale Deposit Jordan". Natural Resources Authority, Amman, and BP Research Centre.

[8] Hufnagel, H. 1980. "Investigation of the El-Lajjun Oil Shale Deposit". Bundesanstalt fur Geowissenschaften und Rohstoffe, Hannover, Technical cooperation Project NO. 78.2156.5.

[9] Abed, A. M. 2000. The geology of Jordan and its environment and water (in Arabic). Publication of the Jordanian Geologists Association, Amman - Jordan.

[10] Alali, J. and Sawaqed, S.(Editors). 2006. Oil Shale Resources Development in Jordan. Unpublished report. Natural Resources Authority, Amman, Jordan.

[11] Besieso, M. 2007. Jordan's Commercial Oil Shale Strategy. $27^{\text {th }}$ Oil Shale Symposium. Colorado School of Mines, Colorado, USA.

[12] Jaber, J.O., Thomas A. Sladek, T.A., Mernitz,S., Tarawneh, T. M. 2008. Future Policies and Strategies for Oil Shale Development in Jordan .Jordan Journal of Mechanical and Industrial Engineering. Vol. 2. No. 1. Pp 31-44. 